\title{
MULHERES COM IDADE IG UAL OU SUPERIOR A 50 ANOS: ações preventivas da infecção pelo HIV
}

\author{
Daniela Angelo de Lima RODRIGUES ${ }^{a}$, N eide de Souza PRAÇA ${ }^{\text {b }}$
}

\section{RESUMO}

T rata-se de pesquisa qualitativa que buscou verificar a adoção de ações preventivas da transmissão do HIV por mulheres com idade igual ou superior a 50 anos, morador as em uma comunidade de baixa renda e atendidas pelo Programa Saúde da Família, no M unicípio de São Paulo. A dotou-se como referencial teórico a Antropologia M édica e, para o tratamento dos dados, o D iscurso do Sujeito Coletivo. Foram entrevistadas 13 mulheres e são apresentados três discursos: valorizando a prevenção; invisibilidade do HIV/ aids; e rejeição à adesão ao preservativo. A análise mostrou que o grupo não se percebia em risco à infecção pela via sexual devido à confiança na fidelidade do parceiro. 0 eventual uso do preservativo foi atribuído somente à curiosidade. As ações preventivas adotadas carecem de embasamento científico. Os resultados al ertam para a necessidade do planejamento e da implementação de intervenções cultural mente embasadas direcionadas ao segmento estudado.

D escritores: Síndrome de imunodeficiência adquirida. Saúde da mulher. Saúde do idoso. Antropologia.

\section{RESUMEN}

Se trata de una investigación cualitativa que buscó verificar la adopción de acciones preventivas de la transmisión del VIH por mujeres con edad igual 0 superior a 50 años, residentes en una comunidad de baja renta y atendidas por el Programa Salud de la Familia, en el municipio de São Paulo, B rasil. Se adoptó como referencial teórico la Antropología M édica y, para el tratamiento de los datos, el Discurso del Sujeto Colectivo. Se entrevistaron 13 mujeres y se presentan tres discurSoS: valorar la prevención; invisibilidad del VIH / SID A; rechazo a la adherencia al preservativo. EI análisis apuntó que el grupo no percibió el riesgo a la infección por la vía sexual a causa de la confianza en la fidelidad del compañero. E I eventual uso del preservativo fue atribuido solamente a la curiosidad. L as acciones preventivas adoptadas carecen de base científica. L os resultados alertan para la necesidad del planeamiento y de la implantación de intervenciones culturalmente basadas direccionada al seguimiento estudiado.

Descriptores: Síndrome de inmunodeficiencia adquirida. Salud de la mujer. Salud de la anciano. A ntropología.

T ítulo: M ujeres con edad igual o superior a 50 años: acciones preventivas de la infección por el VIH .

\section{ABST RACT}

T he present study is a qualitative research which aimed to verify the adoption of preventive measures on the transmission of HIV in 50-year-old women or older, who lived in poor communities and were assisted by the F amily $\mathrm{H}$ ealth P rogram in São P aulo, B razil. M edical A nthropology has been adopted as a theor etical reference, as w ell as the D iscourse of the Collective Individual for data analysis. T hirteen women wereinterview ed and three discourses w ere presented: prevention appreciation, invisibility of HIV/ AIDS and therejection of the use of condom. Theanalysis showed that thegroup did not realizetherisk of contamination through sexual intercourse due to their trust in the partner's loyalty. The casual use of condoms was taken into consideration just out of curiosity. The preventive actions adopted need more scientific support. The results point out the necessity of planning and implementing interventions which are culturally based and directed to the studied segment.

Descriptors: A cquired immunodeficiency syndrome. Women's health. H ealth of the elderly. Anthropology.

$T$ itle: The 50-year-old women or older: preventive actions to the H IV infection.

a E nfer meira O bstétrica, M estre em E nfermagem, D outoranda do Programa de Pós-G raduação em E nfer magem da E scola de E nfer magem da U niversidade de São Paulo (U SP), Coordenadora de Pós-G raduação (L ato Sensu) da U niversidade N ove de Julho (U N IN OVE), São Paulo, Brasil.

${ }^{b}$ Enfermeira Obstétrica, D outora em Enfermagem, Professora Associada (Livre-D ocente) da Escola de Enfermagem da USP, São Paulo, Brasil. 


\section{INT RODUÇÃO}

A Síndrome de I munodeficiência Adquirida (aids), doença causada pelo Vírus da Imunodeficiência H umana (HIV), tem se mostrado uma epidemia multifacetada e de difícil controle. Sendo uma dessas facetas o crescente e silencioso envolvimento da população com idade igual ou superior a 50 anos, fato que tem se configurado em uma situação que requer atenção no cenário nacional.

A relevância da epidemia pode ser evidenciada pela análise de dados epidemiológicos nacionais. A té junho de 2009, foram notificados 544.846 casos de aids no país, destes, 34,6\% correspondentes às mulheres. Entre os casos femininos, 9,7\% são representados por mulheres com 50 anos de idade ou mais, sendo que $97 \%$ se infectaram pela via sexual ${ }^{(1)}$.

Vale citar que a transmissão heterossexual, desde a notificação do primeiro caso de aids, é a via de infecção predominante entre as mulheres com idade acima de 50 anos no Brasil(1). Dado concordante com a J oint $U$ nited $\mathrm{N}$ ations P rogramme on HIV/AIDS (UNAIDS), que com base em dados mundiais, indica que a transmissão heterossexual é a categoria de infecção pelo HIV predominante entre os indivíduos nesta faixa etária(2).

Essa realidade é atribuída à sinergia de fatores, como a existência de terapias mais eficazes que prolongam a vida do infectado pelo HIV, a expansão do número de idosos devido ao aumento da expectativa de vida ao nascer e, em relação às muIheres, as mudanças que ocorrem na vagina, na fase da menopausa, que favorecem a penetração do vírus no organismo durante 0 ato sexual. Além disso, a introdução de medicamentos contra a impotência sexual masculina, medicamentos que minimizam os efeitos da menopausa e lubrificantes vaginais, tem favorecido o prolongamento da vida sexual, com qualidade, resultando no aumento de oportunidades para os idosos infectarem-se pelo HIV (3-7).

T ambém pode-se citar como aspecto que potencializa o risco da população idosa, o predomínio de campanhas voltadas a prevenção do HIV/ aids que não incluem este grupo, reforçando entre os idosos a concepção de que a aids é uma doença restrita à grupos mais joven ${ }^{(8)}$.

U ma possível explicação para a não inclusão dos idosos nas ações de prevenção do HIV/ aids é a persistência da concepção de "velhice assexuada"(9).
Contudo, estudos científicos têm-na desmistificado. A atividade sexual após os 50 anos foi averiguada em pesquisa realizada com 165 homens e mulheres, com idade entre 50 e 66 anos, ser vidores públicos do estado de $\mathrm{M}$ ato $\mathrm{G}$ rosso. Entre os entrevistados, 72,4\% relataram atividade sexual nos seis meses anteriores à pesquisa ${ }^{(10)}$.

0 envolvimento deste segmento populacional na epidemia de HIV/aids, também pode ser atribuído a outros fatores, como à ausência de percepção de risco à infecção pelo H IV eà dificuldade das mulher es para negociar o uso do preser vativo com o parceiro, sobretudo por considerá-lo como método contraceptivo, mas, também, pelo fato de que essa prática não é comum em seu meio(10,11).

A constatação da situação exposta, assim como a reconhecida multiplicidade de fatores envolvidos no fenômeno e o inexpressivo número de publicações nacionais abordando a temática da aids neste segmento populacional, motivaram a realização de uma pesquisa, da qual se extraiu o texto aqui apresentado(12). 0 estudo de maior amplitude buscou responder as questões: a mulher com idade de 50 anos ou mais percebe-se em risco para a transmissão do HIV por via sexual? Esta mulher realiza ações para proteção contra a infecção pel o HIV?

Para responder estas questões, definiu-se o seguinte objetivo: verificar a realização de ações preventivas da transmissão do HIV, por mulheres com idade igual ou superior a 50 anos, moradoras em uma comunidade de baixa renda.

\section{MÉT ODO}

T rata-se de um estudo qualitativo, que teve como referencial teórico a Antropologia M édica, definida como "a abordagem das maneiras pelas quais as pessoas, em diferentes culturas e grupos sociais, explicam as causas dos problemas de saúde, assim como os relacionam aos tipos de tratamento nos quais as pessoas acreditam e os indivíduos a quem recorrem quando adoecem. Além disso, é também o estudo de como essas crenças e práticas relacionam-se às mudanças biológicas, psicológicas e sociais do organismo humano, tanto na saúde como na doença"(13).

A coleta de dados foi realizada em parte da área de abrangência atendida por uma das seis equipes do Programa Saúde da Família (PSF) do Jardim São J orge, na qual uma das pesquisadoras trabalhava como enfermeira na ocasião. Localiza-se 
na zona oeste do M unicípio de São Paulo e, em sua área física, há 14 prédios de um projeto habitacional municipal da década de 1990, e dezenas de casas construídas ilegalmente em terreno invadido.

A escolha do campo foi facilitada pelo contato diário da pesquisadora com o local e a população em potencial. Esta opção baseou-se, também, no reconhecimento de que o grupo cultural estudado, caracterizado como de baixa renda, possui características compatíveis à atual expansão da epidemia de aids no país, como menor renda e/ ou menor escolaridade.

$\mathrm{Na}$ comunidade escolhida para o estudo, no início da coleta de dados, existiam 62 mulheres com idade igual ou superior a 50 anos, destas, 13 participaram do estudo. Este número foi definido durante a coleta de dados, quando se verificou que 0 conteúdo das respostas se repetia, sem qualquer inclusão de novos temas. Foram estabelecidos os seguintes critérios para inclusão das mulheres: ter 50 anos de idade ou mais, ser atendida pelo PSF, morar há pelo menos um ano na comunidade selecionada para a real ização do estudo, e ter história de contato prévio com a pesquisadora para atendimento de saúde.

Vale acrescentar que um dos princípios para a obtenção de dados significativos em pesquisa qualitativa reside no reconhecimento do pesquisador pelo pesquisado. Desse modo, dentre as muIheres do segmento de interesse cadastradas no PSF, por meio da ficha de cadastro familiar, identificaram-se aquelas que atendiam os critérios de inclusão, as quais passaram a ser contatadas aleatoriamente. A coleta de dados ocorreu nos meses de setembro e outubro de 2005. As entrevistas, previamente agendadas, foram obtidas individualmente, na residência das informantes, quando se procurou atender à privacidade de cada mulher.

No momento da entrevista, a pesquisadora preenchia 0 instrumento elaborado para a coleta de dados com registro de identificação/ caracterização das informantes. E m seguida, apresentava a questão norteadora: "F ale como é viver sabendo que existe a aids", iniciando-se a gravação em fita cassete.

A presente pesquisa foi aprovada pelo Comitê de Ética em Pesquisa da Secretaria M unicipal de Saúde de São Paulo, sob o número 084/ 2005. Precedendo a entrevista, todas as informantes assinaram o Termo de Consentimento Livre e E sclarecido ( $T$ CLE) após terem sido orientadas sobre 0 estudo, pela própria pesquisadora, que Ihes garantiu sigilo, anonimato e que seu atendimento pelo PSF não sofreria interrupção caso se recusassem ou desistissem de participar da presente pesquisa. Cada entrevistada recebeu uma via do T CLE enquanto a outra via ficou com a pesquisadora.

\section{T ratamento dos dados}

Todas as entrevistas foram transcritas na íntegra e seus dados foram tratados segundo o método do Discurso do Sujeito Coletivo (DSC), que é uma proposta de organização de dados qualitativos que, neste estudo, se constituiu na fonte verbal ${ }^{(14)}$.

A pós a transcrição literal dos relatos obtidos com cada entrevista, seu conteúdo sofreu inúmeras leituras para identificação dos trechos de interesse para 0 estudo. Em seguida foram extraídas as Expressões-Chave (ECH), que são transcrições de partes do relato das entrevistadas que revelam a essência de seu discurso; e suas respectivas I deias Centrais (IC), que são os nomes/ expressões que descrevem de maneira objetiva o sentido de cada $\mathrm{ECH}$. $\mathrm{O}$ passo seguinte se constituiu no agrupamento das I deias Centrais com similaridade de conteúdo, sempre agregadas às respectivas ECH. D este grupamento construíram-se os discursos, denominados D SC, que expressam a representação social de todos os pesquisados sobre o objeto sob estudo ${ }^{(14)}$

Os discursos são apresentados na primeira pessoa do singular, tendo como objetivo construir a fala de uma pessoa coletiva, como se fosse um sujeito individual, representando dessa maneira, o pensamento compartilhado do grupo sob estudo(14).

Como resultado da pesquisa matriz, a aplicação do método de tratamento dos dados possibilitou a construção de 12 D SC. D estes, sel ecionaramse aquel es que se relacionam às ações de preven ção da infecção pelo HIV, apontadas para o cotidiano das mulher es com idade igual ou superior a 50 anos, moradoras na comunidade campo do estudo.

\section{RESULT ADOS}

N este texto, inicialmente, serão apresentados os dados de car acterização das respondentes e, em seguida, os DSC construídos a partir das respostas à questão aberta empregada durante a entrevista. 


\section{Caracterização das participantes}

Os dados mostraram que a idade das mulheres variou entre 50 e 72 anos; dez tinham entre 50 e 59 anos; nove tinham até três anos completos de estudo; oito referiram renda mensal de até um salário mínimo; cinco eram católicas e oito evangélicas. A atividade de lazer mais citada foi a frequência ao culto religioso, seguida por assistir televisão. Somente duas mulheres haviam se submetido ao teste anti-HIV em algum momento da vida.

Quando da coleta de dados, cinco mulheres viviam relacionamento estável, no entanto, oito tinham história de relacionamento estável anterior à pesquisa, o qual havia sido inter rompido por separação ou por falecimento do parceiro.

Perguntadas sobre suas fontes de informação sobre HIV/ aids, verificou-se que dez mulheres citaram a televisão, cinco referiram conversas com amigos e vizinhos; duas citaram programas de rádio e, outras duas, tiveram como fonte as informações obtidas pelo adoecimento de familiar próximo. A leitura de revistas e cartazes em serviços de saúde foi apontada por uma participante.

\section{D iscurso do Sujeito Coletivo}

D entre os DSC resultantes do tratamento dos dados dos relatos referentes à questão norteadora, neste texto, optou-se pela apresentação de três discursos, narrados a seguir.

\section{DSC-01: Valorizando a prevenção:}

E u já ouvi falar que precisa se cuidar, setem essa doença, tem de se prevenir que é uma doença que acho que não tem cura, né?! P rincipalmente quem tem relação, evitar usando a camisinha, se cuidar enão sair com um aqui e outro "acolá", e não ter uma camisinha. A cho que a pessoa que não se previne é porque é relaxada, né?! E u vejo falar que o casal, mesmo dentro de casa, tem de usar o preservativo, porque às vezes vive com alguém que a gente acha que ele vive só com a gente, mas a gentenão sabe, né?! G eralmente os homens também saem com várias mulheres. Vai confiar em marido hoje? Tem tantas mulheres que pegaram aids dos parceiros eelas nunca traíram os maridos, mas os maridos transmiti ram o vírus para elas, né?! T ambém éimportante procurar fazer os exames, sabe? F azer o H IV para ficar cientequenão tem o vírus eficar tranquilo. A gora outros cuidados, bem, eu não sento em banhei ro nenhum. E u evito porquesesentar, a gente apanha doença. T ambém procuro não sentar em lugar que está muito quen- te, que a pessoa levantou e eu não sei quem é. Se comer no prato que aquela pessoa comeu, se você tomar água naquele copo que a pessoa quetem aids tomou, não pega aids. D iz que através do beijo não tem nada também. $\mathrm{N}$ em a pessoa convivendo junto na mesma casa. 0 corpo, sem ter ferimento, sem te transmitir sangue, nem nada, você não pega.

DSC-02: Invisibilidade do HIV/ aids:

Você sabe que eu nem penso nisso? E u não penso na aids. Sobreisso eu sei quenão tem problema nenhum. É só eu e o meu marido, e eu confio nele, então não tem perigo. Aqui, em São Paulo, eu acho que ele nunca foi homem para isso, para metrair com outra, porqueelejá me traiu, né?! U ma vez, mas eu acho que aqui é impossível. E stá certo que falaram para mim que ele é "muiezero", que, no bar estava bebendo com mulher, né?! A gora se ele saía eu não sei. E le tem muito medo deficar doente, dessas doenças ele tem muito medo. $\mathrm{E}$ tão, nada interfereassi $m$, para mim. E u só fico em casa mesmo, minha casa, meu marido, então não tem essas coisas de aids. Sinceramente eu nunca fiz nada para evitar. N ão previno assim de nada não. Também ele nunca teve nada, eu estou bem e ele está também. E ntão, se você confiar no marido, né?! Se confiar nele, tudo bem, não precisa usar. A cho também que as pessoas que têm suas esposas não vão andar "caçando" outras mulheres por aí. E u também nunca fiz exame porquenunca pediram para fazer, nunca nem postinho nem nada. $M$ as espero que $D$ eus me livre. $E u$ acho que eu não tenho não.

\section{DSC-03: Rejeição à adesão ao preservativo:}

Algumas vezes que eu fui experimentar [ o preservativo] não achei bom e ele também não achou. E le diz que não presta, que não acha bom. U sei porque surgiu, apareceu por aí, mas não é coisa que foi direto não, foram pouquinhas vezes. Foi só para experiência. É horrível, já é sacrifício demais PA ra mim sentir prazer, então, com a camisinha eu acho quefoi pior ainda. E ssa precaução eu não tomo. E u não uso camisinha porque eu não gosto mesmo, só de ouvir o povo, é por isso mesmo que eu acho que já não gosto. E u sei que o certo é usar, né?! M as aqui dentro da minha casa não se usa.

\section{DISCUSSÃO}

Os DSC construídos mostraram a precária valorização da prevenção da infecção pelo HIV pelas mulheres na faixa etária de interesse; visto que se percebem susceptíveis à infecção, contudo, por vias que não possibilitam a real transmissão do ví- 
rus. D ado que sugere a desinfor mações destas muIheres sobre a infecção.

Por outro lado, os DSC sob análise mostraram afirmações concordes com estudo onde as mulheres identificaram a realização do teste anti-HIV como meio para diagnosticar a doença, porém sua reduzida percepção de risco resulta em menos oportunidades para a testagem, pois não procuram por esse tipo de serviço(11).

Ainda que 0 uso do preservativo seja apontado como conduta preventiva de infecção pelo HIV, encontraram-se ideias conflitantes sobre seu uso, pois este foi indicado somente para situações específicas, como nas relações sexuais com parceiros desconhecidos ou em caso de desconfiança da fidelidade do parceiro. A o mesmo tempo, a necessidade de adesão ao preservativo, também, em relacionamentos estáveis relaciona-se à dificuldade em confiar na fidelidade do parceiro, pois acreditam na tendência masculina para a infidelidade e reconhecem que o comportamento infiel do parceiro potencializa o risco de infecção pelo HIV.

D essa forma, os discursos mostraram a reduzida percepção de risco de infecção pelo HIV pela via sexual. N el es transpareceu o sentimento de segurança, garantido pela adoção de comportamentos tidos como protetores da infecção, sendo o principal deles, o relacionamento monogâmico com 0 parceiro. A confiança na fidelidade do companheiro é sua principal garantia de proteção contra a infecção.

Os relatos demonstraram, ainda, a visão prejudicada das mulheres diante da possibilidade de contrair o HIV sexualmente, motivo que as influenciava para a não adesão ao preservativo em suas relações sexuais. Contudo, a contradição é reforçada pelo fato de reconhecerem que os homens são natural mente propensos a se envolver em relacionamentos extraconjugais, assim, demonstraram relevar situações de traições passadas e de atitudes que sugeriam a continuidade desse comportamento do parceiro. Dessa forma, os DSC mostraram que as mulheres não demonstraram preocupação em modificar seu comportamento em relação à prevenção da transmissão do HIV quando o enfoque é o relacionamento sexual.

D a mesma maneira, torna-se evidente que as relações de gênero, permearam a percepção de risco e a decisão para a adoção de medidas preventivas para a transmissão sexual do HIV. As atitudes descritas podem ser justificadas pela construção da sexual idade feminina, compreendida pelo conceito de gênero, que pode ser uma possível explicação para a dificuldade para a prevenção do HIV entre as mulheres. I sto porque, 0 amor, no mundo feminino, adquire forte sentido de abnegação de si mesma em função do outro, caracterizando um exercício constante de silenciar e conformar-se. E m contrapartida, o homem é visto como possuidor de um caráter sexual incontrolável, indomável, que requer satisfação sempre imediata, nunca recusando um relacionamento sexual, mesmo que seja extraconjugal, de modo a, assim, provar sua virilidade ${ }^{(15,16)}$. T ais concepções, talvez possam explicar a atitude passiva dessas mulheres frente à infidelidade do parceiro.

Para justificar a confiança no companheiro, discursaram sobre a crença de que o medo da aids é capaz de impedir a infidelidade conjugal e, assim, acreditavam que seus parceiros não se arriscariam a se infectar pelo HIV, em relações com outras muIheres. Outro dado relevante repousa no fato de que estas mulheres reconheciam o parceiro como saudável.

E videnciaram-se, assim, as contradições apresentadas pelo grupo estudado, referentes ao que realmente poderia potencializar a percepção do risco de se infectar pelo HIV e, assim, motivar a adesão ao preservativo em suas relações sexuais. U ma possível explicação, talvez seja o fato de perceberem a aids como a doença do "outro", ou seja, distante da sua vida regrada e moralmente correta, visto que referiram não realizar ações que as colocassem sob risco. Dessa maneira, embora reconheçam a importância do uso do preservativo para a prevenção da transmissão do HIV, os DSC mostraram que as mulheres nunca ou raramente o utilizavam e, também, não demonstraram intenção de usá-lo.

A ausência de percepção de risco também foi encontrada em pesquisa qual itativa realizada em F Iorianópolis, Santa Catarina,, com 13 pessoas portadoras do HIV. Os resultados demonstraram que antes do diagnóstico os entrevistados não se sentiam vulneráveis à infecção(17).

Estudo nacional realizado no Vale dos Sinos, Rio $\mathrm{G}$ rande do Sul, que teve como objetivo verificar o comportamento e o conhecimento sobre HIV/ aids, também encontrou dados que mostram a não adesão ao preservativo entre os idosos. D entre os 510 frequentadores de grupos de convivência da terceira idade entrevistados, $86,3 \%$ não usavam preser vativo ${ }^{(18)}$. 
Pesquisa realizada em Sydney, A ustrália, por meio do levantamento de dados constantes em 2438 prontuários de pessoas com idade igual ou superior a 50 anos, atendidas em uma clínica especializada em saúde sexual, entre 1993 e 2003, encontrou menos relatos de uso do preservativo entre as mulheres. Entre estas, 19\% referiram ter usado o preservativo em uma ou mais relações sexuais ocorridas nos três meses precedentes à entrevista, enquanto que $54 \%$ dos homens apontaram a mesma resposta(19).

No DSC-03 ficou claro que o uso do preservativo teve como única motivação a curiosidade em experimentá-lo. A lém disso, a não adesão ao preservativo em todas as relações sexuais foi justificada pela interferência negativa na qualidade da relação sexual.

A crença na fidelidade do companheiro e a não val orização de seu passado com relação às atitudes que poderiam tê-lo infectado são fatores que geram o não emprego do preservativo, cuja imagem negativa favorece 0 desinteresse em usá-lo, também, no futuro. Para as mulheres que utilizaram 0 preservativo, a tendência é atribuir-Ihe interferência no prazer durante 0 ato sexual, bem como relacionar seu uso à curiosidade. De onde se deduz que medidas de prevenção da transmissão do HIV não têm impacto suficiente na modificação do comportamento destas mulheres.

Cabe destacar que os gestores de saúde, no B rasil, aparentemente, despertaram para o envolvimento da mulher fora do período reprodutivo na epidemia de HIV/ aids. Visto que a campanha nacional de prevenção à aids para 0 carnaval 2009 teve como slogan: "Sexo não tem idade para acabar. Proteção também não". A ação foi voltada para a prevenção da doença em mulheres acima dos 50 anos após pesquisas nacionais demonstrarem que este grupo, apesar de afetado pela epidemia, reluta em aderir ao uso do preservativo em suas relações sexuais ${ }^{(20)}$.

\section{CONSIDERAÇÕES FINAIS}

Os achados deste estudo sugeriram desinformação da mulher com idade igual ou superior a 50 anos sobre o HIV/ aids, com per petuação de abordagens do senso comum nas ações de prevenção sexual da infecção pelo HIV.

Os dados são um alerta para os profissionais de saúde que atuam com indivíduos na faixa etária de interesse deste estudo. T al afirmação realça a necessidade de sensibilização sobre a realidade da vida sexual deste segmento populacional que continua ativo, sendo realizada sem proteção, sujeitando seus membros a comportamentos de risco para a infecção pelo HIV. D essa maneira, julga-se que a discussão desses aspectos, durante consultas com os idosos, seja de fundamental importância para a divulgação de informações e para mudanças de comportamento dessa população.

As intervenções, que visam à prevenção da transmissão do HIV, al ém de considerarem a disseminação do conhecimento sobre a infecção, devem, também, considerar temas de difícil abordagem, por serem impregnados de valores morais, tais como a percepção de risco e as questões de gênero, aspectos que se apresentaram nos discursos e que mostram ser deter minantes à adesão a comportamentos preventivos.

Os achados desta pesquisa evidenciam a necessidade de as intervenções para a prevenção da transmissão do HIV serem culturalmente embasadas, consider ando as crenças, as infor mações eas necessidades do grupo-alvo e, dessa maneira, despertá-lo para reflexões e para provocar alter ações de comportamento diante da epidemia de aids.

A o se concluir este texto, reforça-se a importância de um movimento contínuo para a construção do conhecimento científico nacional sobre aids na população de mulheres com 50 anos de idade ou mais e a importância do trabalho interdisciplinar, em programas de intervenção que propiciem a redução do número de infectados pelo HIV também nesta faixa etária.

\section{REFERÊ NCIAS}

1 M inistério da Saúde (BR), Coordenação $N$ acional de DST eAids. Dados de aids [ Internet] . Brasília (D F ); 2009 [ citado 2010 jan 20]. Disponível em: http:/ / www2.aids.gov.br/ cgi/ tabcgi.exe?tabnet/ br.def.

2 Joint United $\mathrm{N}$ ations Programme on HIVAIDS. I mpact of aids on older populations [I nternet]. G eneva; 2002 [ cited 2004 Sept 30] . Available from: http:/ / data.unaids.org/ publications/ F act-Sheets02/ fs_older_en.pdf.

3 Catania JA, T urner H, Kegeles SM, Stall R, Pollack $L$, Coates T J. Older A mericans and aids: transmission risks and primary prevention research needs. Gerontologist. 1989;29(3):373-81. 
4 E Idred S, W est L. HIV prevalence in older adults. Can N urse. 2005;101(9):20-3.

5 Simone M J, A ppelbaum J. HIV in older adults. G eriatrics. 2008;63(12):6-12.

6 Pereira ECA, Schmitt ACB, Cardoso M RA, Aldrighi JM. Tendência da incidência e da mortalidade por aids em mulheres na transição menopausal e pós-menopausal no Brasil, 1996-2005. Rev Assoc M éd Bras. 2008:54(5):422-5.

7 Jacobs RJ, T homlison B. Self-silencing and age as risk factors for sexually acquired HIV in midlife and older women. J Aging Health. 2009;21(1):102-28.

8 Pratt G, G ascoyne K, Cunningham K, T unbridge A. Humam immunodeficiency virus (HIV) in older people. Age A geing. 2010;39(3):289-94.

9 M elo M R, Gorzoni M, M elo KC, M elo E. Síndrome da imunodeficiência adquirida no idoso. Diag T ratamento. 2002;7(2):13-7.

10 Olivi M, Santana RG, M athias TAF. Behavior, knowledge and perception of risks about sexually transmitted diseases in a group of people over 50 years old. Rev Latino-Am Enfermagem. 2008;16(4):67985.

$11 \mathrm{G} \mathrm{oodroad} \mathrm{BK.} \mathrm{HIV} \mathrm{and} \mathrm{aids} \mathrm{in} \mathrm{people} \mathrm{older} \mathrm{than} 50$ : a continuing concern.J Gerontol N urs. 2003;29(4): 18-24.

12 Lima D A . A mulher com idade igual ou superior a 50 anos e a epidemia de aids: percepção e ações de moradoras de uma comunidade de baixa renda [ dissertação] . São Paulo: E scola de E nfermagem, U niversidade de São Paulo; 2006.

\section{Endereço da autora / Dirección del autor / Author's address:}

D aniela Angelo de Lima Rodrigues

Rua D eputado Salvador Julianelli, s/ n,

Barra Funda

Coordenação da Pós-G raduação

(L ato Sensu), 9a andar

01156-080, São Paulo, SP

E-mail: daniangelo@uninove.br
13 A brangência da antropologia médica. In: H elman CG. Cultura, saúde e doença. 4⿳亠 ed. São Paulo: Artmed; 2003. p. 11-23.

14 L efèvre F, L efèvre AM C. 0 discurso do sujeito coletivo. $2^{\text {a }}$ ed. Caxias do Sul: E DU CS; 2003.

15 Barbosa RM, Villela W V. A trajetória feminina da AIDS. In: Parker R, Galvão J, organizadores. Quebrando o silêncio: mul heres e AID S no Brasil. Rio de Janeiro: Relume-Dumará; 1996. p. 17-32.

16 G uerriero I, Ayres J R, Hearst N . M asculinidade evulnerabilidade ao HIV de homens heterossexuais, São Paulo, SP. Rev Saúde Pública. 2002;36 Supl 4:50-60.

17 M aliska ICA, Padilha M I, Vieira M , Bastiani J. Percepções esignificados do diagnóstico e convívio com o HIV/ aids. Rev G aúcha Enferm [ I nternet] . 2009 [ citado 2009 nov 30];30(1):85-91. Disponível em: http:/ / www.seer.ufrgs.br/ index.php/ Revista G aucha deE nfermagem/ article/ view/ 5966/ 6567.

18 L azzarotto AR, Kramer AS, Hadrich M, Tonin M, Caputo P, Sprintz E. O conhecimento de HIV/aids na terceira idade: estudo epidemiológico no Vale do Sinos, Rio G rande do Sul, Brasil. Ciênc Saúde Colet. 2008;13(6):1833-40.

19 Bourne C, M inichiello V. Sexual behaviour and diagnosis of people over the age of 50 attending a sexual health clinic. Australas J A geing. 2009;28(1):32-6.

20 M inistério da Saúde (BR), Secretaria E special de Políticas para as $\mathrm{M}$ ulheres. Prevenção à aids no carnaval 2009 [ I nternet] . Brasília (D F); 2009 [ citado 2009 abr 20]. Disponível em: http:// portal.saude. gov.br $/$ portal $/$ saude/ area.cfm?id_area=137\& pagina= dspD etalheC ampanha\&co_seq_campanha=2546.

Recebido em: 16/ 03/ 2010

A provado em: 16/ 05/ 2010 